\title{
Direitos e garantias de igualdade para a formação cidadã dos sujeitos
}

\author{
Rights and guarantees of equality for the citizen formation of subjects \\ Derechos y garantías de igualdad para la formación ciudadana de sujetos
}

Recebido: 13/10/2021 | Revisado: 20/10/2021 | Aceito: 26/10/2021 | Publicado: 29/10/2021

Denise da Costa Dias Scheffer

ORCID: https://orcid.org/0000-0002-1755-542X

Universidade de Cruz Alta, Brasil

E-mail: dcdscheffer@gmail.com

Diego Pascoal Golle

ORCID: https://orcid.org/0000-0002-5264-8007

Universidade de Cruz Alta, Brasil

E-mail: dgolle@unicruz.edu.br

Marcelo Cacinotti Costa

ORCID: https://orcid.org/0000-0002-6622-3229

Universidade de Cruz Alta, Brasil

E-mail: marcosta@unicruz.edu.br

Daiane Caroline Tanski

ORCID: https://orcid.org/0000-0003-0456-1393

Universidade de Cruz Alta, Brasil

E-mail: daitans@hotmail.com

Tiago Anderson Brutti

ORCID: https://orcid.org/0000-0003-3216-4221

Universidade de Cruz Alta, Brasil

E-mail: tbrutti@unicruz.edu.br

Ciro Portella Cardoso

ORCID: https://orcid.org/0000-0002-2233-359X

Universidade de Cruz Alta, Brasil

E-mail: ciro.cardoso@hotmail.com

\begin{abstract}
Resumo
Os direitos e garantias de igualdade são ferramentas sociais na busca constante do tratamento igualitário aos sujeitos diante do ordenamento jurídico vigente, buscando a comunicação entre sociedade, sujeito, legislação e garantias, promovendo a construção da reflexão crítica dos sujeitos em suas interações sociais. Permeando a discussão da abordagem da temática de direitos e garantias dos sujeitos e seu processo formativo e crítico na vida em sociedade, o objetivo deste trabalho foi analisar e discutir os diretios e garantias enquanto componentes formativos das concepções dos sujeitos acerca do coletivo. A metodologia baseou-se na abordagem qualitativa, por meio de um estudo bibliográfico, cuja a análise é pautada de cunho exploratória do tema delimitado. Durante o desenvolvimento críticoreflexivo da pesquisa e escrita, evidenciou-se conceitos doutrinários basilares de direitos, liberdade, igualdade, perfazendo menções dialógicas no campo jurídico, acerca de autores constituicionalistas, contextualizando portanto, a emancipação social da formação cidadão dos sujeitos.
\end{abstract}

Palavras-chave: Igualdade; Sociedade; Ordenamento jurídico.

\begin{abstract}
Equality rights and guarantees are social tools in the constant search for equal treatment of subjects in the face of the current legal system, seeking communication g society, subject, legislation and guarantees, promoting the construction of critical reflection of the subjects in their social interactions. Permeating the discussion of the approach of the subject of rights and guarantees of the subjects and their formative and critical process in life in society, the main of this work was to analyze and discuss the rights and guarantees as formative components of the subjects' conceptions about the collectivity. The methodology was based on the qualitative approach, through a bibliographic study, whose analysis is guided by an exploratory nature of the delimited theme. During the critical and reflexive developments of research and writing, basic doctrinal concepts of rights, freedom, and equality were evidenced, with dialogical mentions in the field of laws, about constitutionalist authors, contextualizing, therefore, the social emancipation of the citizen formation of the subjects.
\end{abstract}

Keywords: Equality; Society; Legal order.

\section{Resumen}

La igualdad de derechos y garantías se presentan como herramientas sociales en la búsqueda constante de la igualdad de trato de los sujetos en el ordenamiento jurídico actual. Buscar la comunicación entre sociedad, sujeto, legislación y 
garantías, promoviendo la construcción de una reflexión crítica de los sujetos en sus interacciones sociales. Permeando la discusión sobre el abordaje del sujeto de derechos y garantías de los sujetos y su proceso formativo y crítico en la vida en sociedad, este artículo busca analizar y discutir las directrices y garantías como componentes formativos de las concepciones de los sujetos sobre lo colectivo. La metodología se basa en el enfoque cualitativo, a través de un estudio bibliográfico, cuyo análisis se guía por un carácter exploratorio del tema delimitado. Durante los desarrollos críticos y reflexivos de la investigación y la escritura, se evidencian conceptos doctrinales básicos de derechos, libertad, igualdad, haciendo menciones dialógicas en el ámbito jurídico, sobre autores constitucionalistas, contextualizando, por tanto, la emancipación social de la formación ciudadana de los sujetos.

Palabras clave: Igualdad; Sociedad; Ordenamiento jurídico.

\section{Introdução}

Os direitos e garantias elencadas no ordenamento jurídico, no campo da legislação atual, dispostos na Constituição Federal de 1988, denominam-se acerca da igualdade dos sujeitos na sociedade, os quais dependem basicamente do espaço e do cumprimento de direitos e deveres éticos e morais que cada sujeito por meio de suas necessidades individuais e coletivas. Desta forma, é fundamental que os sujeitos usufruam seus direitos constitucionais garantidos, além da responsabilidade na constância de seus deveres.

A Constituição Federal de 1988 ordena aparatos legais que garantem o igualitarismo de normas de convivência entre os sujeitos. Com o passar dos tempos, o crescimento populacional, a falta de recurso, a desordem e a desigualdade social dissiparam diversidades diante dos direitos e garantias existentes na sociedade e reconhecidos legalmente conforme salienta Bonavides (2004, p. 44), as pessoas e os Estados são imprescindíveis para a existências de todos os direitos e garantias fundamentais, para que assim o ordenamento jurídico trabalhe em sintonia.

Diante do exposto, o objetivo do artigo é analisar a importância da reflexão formativa dos sujeitos diante dos direitos de igualdade na sociedade, pelo viés da legalidade, onde cada indivíduo, pautado nas liberdades e nas garantias normativas devem perseguir a busca constante formativa da cidadania. Utilizando embasamento bibliográfico, acerca da pesquisa qualitativa, conforme expõe Knechtel (2014, p. 85), a pesquisa quantitativa é uma modalidade de pesquisa que atua sobre um problema humano ou social [...], incluindo, portanto, o conhecimento direcionado à temática proposta de pesquisa e contextualização.

O artigo aborda a discussão acerca do campo jurídico, pautado nos direitos e garantias constitucionais, elencando sua conceituação enquanto evento social normatizado de diretrizes da vida em sociedade, acerca da liberdade, da democracia, no senso comum, nos valores éticos e morais, refletindo desta forma o processo formativo dos sujeitos enquanto cidadãos e sua participação no coletivo social, evidenciando a valorização social do respeito, responsabilidade e dignidade humana. Para a reflexão formativa dos sujeitos no campo da legalidade e a cidadania.

\section{Referencial Teórico}

Tema de constante exposição acerca das concepções sociais da vida em sociedade, das normas garantidoras da igualdade e da aplicabilidade dos direitos e garantias fundamentais elencadas no ordenamento jurídico vigente, os direitos fundamentais enfatizam a trajetória evolutiva de liberdades democráticas, da organização social de convivências entres os sujeitos, baseado na paz e na coletividade. Elencando a Constituição Federal de 1988, como importante marco positivista de normativas responsáveis e libertas de distinção entre os sujeitos.

Os direitos fundamentais são essenciais para a organização da vida em sociedade e assim afirma Baruffi (2009, p. 125) sobre a necessidade da cooperação mútua entre os homens:

O homem normal tem por vocação não viver só; necessário que haja cooperação mútua. Aristóteles já dizia que o homem é por natureza um animal político, destinado a viver em sociedade, não só em vista da existência material, 
mas, sobretudo, em vista da vida feliz. Ninguém é feliz sozinho; o homem solitário, que nada precisa por bastar-se a si próprio é um bruto ou um deus.

Desta forma, tem-se a formação do Estado Democrático de Direito, adotado pelo ordenamento jurídico do Brasil, visto que a democracia é, comumente definida, como o governo do povo, para o povo e pelo povo. Neste viés, Dahl (2001, p. 26), afirma que a democracia visa proporcionar o máximo de oportunidades para os cidadãos participarem das decisões políticas. Garantindo a participação ativa dos sujeitos no processo eleitoral, liberto e democrático de escolha de seus representantes e exercendo sua cidadania livre, promovendo o respeito as escolhas e a organização deliberativa das normas emanadas dos direitos e deveres dos sujeitos.

Para tanto, o doutrinador Ferreira Filho (2012, p. 97-98), explica que os cidadãos precisam ter um grau mínimo de desenvolvimento físico e psicológico para firmar sua vontade no mundo externo e, consequentemente, poder realizar sua participação na forma de governo democrática, visto que o trato com a coisa pública requer senso de responsabilidade:

Para que o indivíduo se possa governar por si no mundo, exige o direito universal que atinja uma certa idade que faz presumir o seu amadurecimento. Da mesma forma, para que um povo se possa governar, é preciso que atinja certo grau de maturidade que não se resume na maioridade de seus membros, os eleitores. O governo do povo pelo povo pressupõe em primeiro lugar um certo nível cultural (e não apenas um certo nível de alfabetização) desse povo. [...] É preciso que, em segundo lugar, esteja livre de dominações tradicionais que o prendam a chefes como cliente, ou vassalo. É indispensável, em terceiro lugar, que tenha um mínimo de instrução que o habilite a compreender e apreciar a informação. Urge ainda que esse povo esteja de acordo sobre qual seja o governo legítimo. Cumpre também que tenha senso de responsabilidade, tolerância e respeito pelos dissidentes.

Seguindo a temática, o estudioso Ferreira Filho (2012, p. 95) afirma acerca dos principais valores que são inerentes à forma de governo democrática:

Fundamentalmente são dois valores que inspiram a democracia: liberdade e igualdade, cada um destes valores, é certo, com sua constelação de valores secundários. Não há concepção da democracia que não lhes renda vassalagem, ainda que em grau variabilíssimo. E pode-se até, conforme predomine este ou aquele valor, distinguir as concepções liberais das concepções igualitárias da democracia. A liberdade de cada um e de todos é, assim, inerente à democracia.

Os direitos fundamentais estão previstos no artigo $5^{\circ}$ da Constituição Federal de 1988 e têm o papel, dentro do Estado Democrático de Direito, de limitar o poder estatal estabelecendo regras fundamentais. Estas regras fundamentais constituem cláusulas pétreas e, com isso, o Poder Legislativo não pode revogá-las. Promovendo desta forma, a organização civil de normas diretivas para a vida em sociedade, pautadas no humanitarismo de direitos, nas concepções democráticas de enfrentamento as desigualdades sociais perante a coletividade.

Casado Filho ressalta (2012, p. 52) que o direito à dignidade da pessoa humana é o principal valor que deve orientar e fundamentar todo e qualquer exercício de poder na democracia. Visto que se trata de um direito previsto no primeiro artigo da Constituição Federal de 1988, o qual elege a dignidade da pessoa humana como fundamento da República e do Estado Democrático de Direito que ali foram instituídos. Estes preceitos são preconizados enquanto emancipação dos povos, e garantidores do desenvolvimento social da coletividade, pautados nas normas coletivas sociais dos sujeitos.

Os direitos fundamentais também são importantes para a população, visto que, incorpora o cidadão como sujeito de direitos e conforme explana Pinho (2012, p. 201), os direitos fundamentais são necessários para assegurar a todos uma existência digna, livre e igual. Não basta portanto ao Estado reconhecer os direitos formalmente, mas sim buscar concretizálos, incorporá-los no dia a dia dos sujeitos para sua efetiva aplicabilidade normativa constitucional.

Barroso (2020, p. 430) ressalta, acerca dos direitos fundamentais: 
Os direitos fundamentais, que correspondem aos direitos humanos incorporados aos ordenamentos jurídicos internos. Direitos humanos são uma combinação de conquistas históricas, valores morais e razão pública, fundados na dignidade humana, que visam à proteção da vida, da liberdade, da igualdade e da justiça. E - por que não? - também representam a busca da felicidade.

Já nas palavras de Moraes (apud Moraes, 2016, p. 134), o autor retoma uma fala de Canotilho, acerca da função dos direitos fundamentais:

Assim, os direitos fundamentais cumprem, no dizer de Canotilho, "a função de direitos de defesa dos cidadãos sob uma dupla perspectiva: (1) constituem, num plano jurídico-objectivo, normas de competência negativa para os poderes públicos, proibindo fundamentalmente as ingerências destes na esfera jurídica individual; (2) implicam, num plano jurídico-subjectivo, o poder de exercer positivamente direitos fundamentais (liberdade positiva) e de exigir omissões dos poderes públicos, de forma a evitar agressões lesivas por parte dos mesmos (liberdade negativa)".

Os direitos fundamentais não são previstos apenas para os sujeitos em caráter individualizador, mas na constância pertinente a coletividade. Desta forma, os direitos fundamentais coletivos vislumbram a promoção da proteção de grupos socialmente vulneráveis, tendo como exemplos, o direito do consumidor, a proteção da criança e do adolescente, prevenção contra violência as mulheres, prevenção de preconceito racial, aliados a outros temas normatizados acerca da Constituição Federal de 1988:

A Constituição de 1988 foi a primeira a estabelecer direitos não só de indivíduos, mas também de grupos sociais, os denominados direitos coletivos. As pessoas passaram a ser coletivamente consideradas. Por outro lado, pela primeira vez, junto com direitos foram estabelecidos expressamente deveres fundamentais. Tanto os agentes públicos como os indivíduos têm obrigações específicas inclusive a de respeitar os direitos das demais pessoas que vivem na ordem social. (Pinho, 2012, p. 208).

Ademais, a Constituição Federal atualmente vigente no Brasil foi a primeira doutrina jurídica a prever regras fundamentais à determinados grupos sociais e esses direitos fundamentais coletivos, que visam proteger um determinado grupo socialmente vulnerável, como, por exemplo, os consumidores, a criança e adolescente, mulheres, negros, como alguns exemplos, provocando portanto a visualização dos preceitos igualitários diante de perspectivas minoritárias do alcance e obtenção de direitos, referenciando o anseio de liberdade e igualdade entre os sujeitos e a garantia da evolução responsável dos preceitos normativos da vida em sociedade.

\section{Metodologia}

O texto manifesta formato viabilizado em seu conteúdo a partir de leituras doutrinárias e pesquisa bibliográfica acerca da discussão da igualdade e da cidadania no campo jurisdicional legal. De acordo com Pereira et al. (2018, p. 13), o conhecimento pode ser adquirido de diversas formas: sensação, percepção, imaginação, memória, linguagem, raciocínio e intuição. Através do método qualitativo e de acordo com as palavras de Knechtel (2014, p. 101), a pesquisa qualitativa, leva em consideração as motivações, crenças, valores e representações encontradas nas relações sociais.

A pesquisa busca analisar e demonstrar dentre as doutrinas relacionadas, para que estas esclareçam a importância do semear da igualdade para o crescimento e formação social dos sujeitos. Nas palavras de Gil (2002, p. 17), a pesquisa desenvolve-se ao longo de um processo que envolve inúmeras fases, desde a adequada formulação do problema até a satisfatória reflexão e apresentação dos resultados a partir de consulta da Constituição Federal de 1988, doutrinadores constitucionalistas e artigos científicos acerca da temática proposta dos direitos e garantias constitucionais dos sujeitos. 


\section{Resultados e Discussão}

Os sujeitos constroem seu espaço para sobreviver na vida em sociedade, isso de forma organizada, em uma relação contemporânea de vivências e saberes elevados a formação dos sujeitos enquanto cidadãos, trazendo portanto o dinamismo e o social para sua convivência em grupo e proporcionando a busca da igualdade social na formação dos sujeitos, a desigualdade dos direitos é a primeira condição para que haja direitos, segundo Nietzsche (2018, p. 13).

Sobre a quesito social da sociedade, Michaliszyn (2007, p. 41) explica:

As relações por nós estabelecidas em sociedade são definidas através das estruturas sociais, que se organizam por meio de instituições sociais. Estas agem como órgãos ou forças que regulam as ações humanas, definindo os caminhos a serem trilhados e estabelecendo as consequências pela adoção de modelos desviantes e, portanto, indesejáveis a estrutura social.

Diante do exposto, fica claro que o comportamento social deriva das relações de convívio, pelas regras e valores determinados por cada um, para que assim seja feita a construção de elementos fundamentais da vida como a vida na educação, na política e na economia. De acordo com Silveira et al. (2021). Mesmo que cada indivíduo possua seu tipo social individualizado, precisa da vivência em grupo para o funcionamento da sociedade, atentando para as questões sociais, educacionais, políticas, históricas, econômicas e ambientais.

O papel de cada indivíduo é exercido individualmente, com ações distintas, mas que geram fatos para a coletividade, assim cada um constrói sua história no grupo social que se transforma devido a responsabilidade de todo o indivíduo em sua comunidade, de forma que a parte social se modifica com as inovações que o igualitarismo traz. Tratar os sujeitos de forma emancipatória e respeitando sua realidade, perfaz o caminho para o respeito a humanidade, refletido a responsabilidade individual diante do coletivo, para o bom andamento da vida em sociedade.

Segundo o autor Rui Barbosa (1985, p. 23), sobre a igualdade, reflete-se:

A regra da igualdade não consiste senão em quinhoar desigualmente aos desiguais, na medida em que se desigualam. Nesta desigualdade social, proporcionada à desigualdade natural, é que se acha a verdadeira lei da igualdade. Tratar com desigualdade a iguais, ou a desiguais com igualdade, seria desigualdade flagrante, e não igualdade real leis.

Diante deste processo, Elias (1994, p. 8) complementa:

A sociedade pré-define para nós esse mecanismo simbólico fundamental com o qual apreendemos o mundo, ordenamos nossa experiência e interpretamos nossa própria existência, como também fornece nossos valores, nossa lógica e o acervo de informação que constitui nosso conhecimento.

Assim é preciso compreender e refletir os processos responsáveis pela construção da sociedade e suas características normativas, fazendo assim modelos de convivência, construindo a identidade social do país, decorrente da relação entre sujeitos. Nas palavras de Silveira; Lorenzetti; Scheffer; Golle (2021), os sujeitos precisam compreender que apresentam direitos e deveres, portanto, devem atuar como líderes na sociedade.

Considerando as exposições acima citadas Kemp (2001, p. 76) considera o processo sob sua ótica:

As noções que construímos socialmente de igualdade e diferença são a moeda do jogo de construção das identidades. A cultura proporciona referenciais a partir dos quais os atores sociais acessam os elementos do cenário de conduta para desempenhar seus papéis, pois, com o propósito de demarcar lugares, manipulamos socialmente nossa identidade, assim como a de outros. Isso revela no fato de que em cada contexto social enfrentado, recombinamos os elementos de nossa identidade, ressaltando alguns ou ocultando outros, a identificação é sempre referencial, relacional e combinada. 
Desse modo, a realidade vira um processo de internalização com a realidade social imposta para garantir temas que regulam relações sociais na estrutura da sociedade, mesmo assim a relação estabelecida pelos indivíduos fica de modo singular, sempre lembrando que sozinho ninguém modifica nada, precisa-se sempre inserir esta singularidade no contexto social para relacionar com a coletividade, assim, favorecendo um processo libertador e emancipatório para as (con)vivências sociais (Silveira; Lorenzetti, 2021).

Portanto a sociedade exerce poder normativo sobre cada indivíduo, e a fiscalização fica definida pelo papel social exercido por cada um, sua atuação social e seu desempenho em oportunidades, utilizando-se assim do igualitarismo e da diversidade para o processo de socialização. Desempenhar o papel social de cada sujeitos, diante da igualdade, dos direitos e deveres, da responsabilidade social basilar enquanto protagonista, eleva o grupo a condição mútua de vida coletiva.

Conforme salienta Elias (1994, p. 34):

Ao nascer, cada indivíduo pode ser muito diferente, conforme sua constituição natural. Mas é apenas na sociedade que a criança pequena, com suas funções mentais maleáveis e relativamente indiferenciadas, se transforma num ser mais complexo. Somente na relação com outros seres humanos é que a criatura impulsiva e desamparada que vem ao mundo se transforma na pessoa psicologicamente desenvolvida que tem caráter de um indivíduo e merece o nome de ser humano adulto.

E diante da convivência em sociedade, da formação dos sujeitos enquanto cidadãos, seus direitos e deveres, ampliando saberes e conhecimentos inerentes a pessoa humana, Elias (1994 p. 45), expõe seu pensamento dizendo:

Os atos de muitos indivíduos distintos, especialmente numa sociedade tão complexa quanto a nossa, precisam vincular-se ininterruptamente, formando longas cadeias de atos, para que as ações de cada indivíduo cumpram suas finalidades. Assim, cada pessoa singular está realmente presa por viver em permanente dependência funcional de outras; ela é um elo nas cadeias que ligam outras pessoas, assim como todas as demais, direta e indiretamente.

Coerente as normativas vivenciadas dos sujeitos, sua participação ativa enquanto cidadão, sua prerrogativa atribuída de direitos e deveres elencados no ordenamento jurídico perfaz as diretrizes fundamentais formativas das convicções de (con) vivências em grupo e a organização dos preceitos éticos e morais diante do conjunto cultural, familiar, educacional, social e profissional na vida em sociedade. A consolidação formativa dos sujeitos na narrativa constitucional, nas palavras de Scheffer (2021), percorre a construção no campo social dos valores éticos e morais, em prol da efetiva consolidação da garantia prática da dignidade da pessoa, respeitando as relações interpessoais nas diretrizes coletivas de cidadania aos sujeitos para a vida em sociedade.

\section{Considerações Finais}

O Estado, enquanto ente garantidor das normativas findadas no campo da dignidade da pessoa humana, da igualdade e dos direitos e deveres, constitui a socialização das diretrizes colaborativas individuais no processo formativo do coletivo, pautadas no respeito aos sujeitos, promovendo sua liberdade crítica-reflexiva na busca por seus direcionamentos pessoais oriundos de valores éticos e morais, positivados no ordenamento jurídico e emancipatório acerca do ordenamento jurídico, afim de satisfazer a organização de sua civilização.

Indivíduos, diante dos preceitos legais diretivos, demarcam posicionamentos baseados na igualdade, na construção reflexiva dos sujeitos, diante de seus direitos e deveres, fazendo parte do grupo identificado como sociedade, na condição de ser humano, pela necessidade de convivência, criando assim vínculos com outras pessoas, laços de amor, amizade e afeto, para assim viver civilizado, tratando desta forma da estrutura social. 
Apresenta-se a partir do objetivo da pesquisa, o enfoque reflexivo que, para a sobrevivência da estrutura social do país é preciso que cada indivíduo ocupe seu espaço, viva de forma organizada e cumpra sua participação individual, completando suas tarefas e obrigações estruturais, percorrendo a liberdade democrática dos saberes jurídico acerca dos direitos e deveres, fomentando valores éticos e morais diante do respeito, da dignidade da pessoa, da igualdade, inclusão e a diversidade de povos convivendo em harmonia na sociedade.

Portanto, a pesquisa realizada acerca da temática proposta promove o cumprimento acerca do objetivo do artigo, em analisar a importância da reflexão formativa dos sujeitos diante dos direitos de igualdade na sociedade, pelo viés da legalidade, onde cada indivíduo, pautado nas liberdades e nas garantias normativas devem perseguir a busca constante formativa da cidadania, promovendo o viés crítico para promover novas reflexões em pesquisas da temática, gerando novos debates no campo acadêmico-científico.

\section{Agradecimentos}

Agradeço em especial a Coordenação de Aperfeiçoamento de Pessoal de Nível Superior - CAPES, pela atual bolsa de pesquisa para o curso de Mestrado Acadêmico em Práticas Socioculturais e Desenvolvimento Social dos autores. O fomento possibilita o desenvolvimento desta pesquisa, sua elaboração escrita e a oportunidade de novas reflexões no campo da pesquisa científica.

\section{Referências}

Barroso, L. R. (2020). Curso de direito constitucional contemporâneo: os conceitos fundamentais e a construção do novo modelo. 9. ed. São Paulo: Saraiva Educação.

Baruffi, H. (2009). Direitos fundamentais sociais: Estudos em homenagem aos 60 anos da declaração universal dos direitos humanos e aos 20 anos da Constituição Federal. Dourados, MG: UFGD.

BonavideS, P. (2004). Curso de Direito Constitucional. (14 ${ }^{\mathrm{a}}$. ed.): Malheiros.

Brasil (1988). Constituição da República Federativa do Brasil. In: Diário Oficial da República Federativa do Brasil, Brasília, DF.

Casado Filho, N. (2012). Direitos humanos e fundamentais. São Paulo: Saraiva.

DahL, R. (2001). Sobre a democracia. Brasília: editora universidade de Brasília.

Elias, N. (1994). A sociedade dos indivíduos. Rio de Janeiro: Zahar.

Ferreira Filho, M. G. (2012). Curso de direito constitucional. (38ª . ed.,) rev. e atual. São Paulo: Saraiva.

Gil, A. C. (2002). Como elaborar projetos de pesquisa, (4a. ed.): Atlas.

Kemp, K. (2001). Identidade Cultural. In: Guerreiro, S (Org). Antropos e Pisque: o outro e sua subjetividade. São Paulo: olho D’agua.

Knechtel, M. do R. (2014). Metodologia da pesquisa em educação: uma abordagem teórico-prática dialogada. Curitiba: Intersaberes.

Michaliszyn, M. S. (2007). Educação e Diversidade. Curitiba: IBPEX.

Moraes, A. D. (2016). Direito constitucional. (32a . ed.): Atlas.

Nietzsche, F. (2018) Humano Demasiado Humano. Tradução de Antônio Carlos Braga. Ed. Lafonte, São Paulo.

Pereira, A. S., Shitsuka, D. M., Parreira, F. J., \& Shitsuka, R. (2018). Metodologia da pesquisa científica. $1^{\mathrm{a}}$ ed. UAB/NTE/UFSM. Universidade Federal de Santa Maria: Santa Maria.

Pinho, R. C. R. (2012) Teoria geral da constituição e direitos fundamentais. (12ª ed.): Saraiva.

Scheffer, D. C. D. (2021). Didática da formação de professores sobre a abordagem dos direitos humanos pelo educador como formador do cidadão. Research, Society and Development. 10(12), 1-7.

Silveira, D. P., Lorenzetti. L., Scheffer, D. C. D., \& Golle, D. P. (2021). Diálogos sobre educação ambiental com escolares: um enfoque na educação ambiental crítica. Research, Society and Development. 10(3), 1-8. 
Research, Society and Development, v. 10, n. 14, e150101421748, 2021

(CC BY 4.0) | ISSN 2525-3409 | DOI: http://dx.doi.org/10.33448/rsd-v10i14.21748

Silveira, D. P., \& Lorenzetti, L. (2021). Estado da arte sobre a educação ambiental crítica no Encontro Pesquisa em Educação Ambiental. Praxis \& Saber. 12(28), 1-15.

Silveira, A. P., Silveira, D. P., Bassan, J. S., Silva, J. C. S., Scheffer, D. C. D., \& Souza, V. S. (2021). A etapa de observação e suas contribuições no campo da educação: uma análise na formação de professores. Research Society and Development. 10(4), 1-8.

Souza, R. B. de. (1985) Correspondência. Rio de Janeiro: Ed. Rigel. 